\title{
PENGARUH PENDAMPINGAN PENDIDIKAN KESEHATAN REPRODUKSI TERHADAP KEMAMPUAN PENGAMBILAN KEPUTUSAN DALAM KEHIDUPAN SEKSUAL SANTRIWATI
}

\author{
Wiwik Afridah \\ Program Studi S1 Kesehatan Masyarakat, Fakultas Kesehatan \\ Universitas Nahdlatul Ulama Surabaya \\ Email: wiwik@unusa.ac.id
}

\begin{abstract}
To develop an awareness of healthy behaviours for adolescents, care and understanding are needed as a form of service and the delivery of information on the importance of reproductive health as a way to determine future choices. Aiming to provide assistance to female students on reproductive health education through peer education for 12 times activities that provide students with the ability to make decisions on the selection of their sexual lives. This type of research is cross-sectional. The target sample of 40 people from a population of 415 people, with simple random sampling technique. Data collection using a questionnaire. Tabulation and data analysis with ChiSquare.The results showed that most (65\%) respondents did not routinely participate in mentoring through peer education, the majority (52.5\%) respondents were unable to make decisions, the test chi-square found a meaningful relationship between assisting reproductive health education with decision-making abilities towards selection sexual life of female students at Al-Jihad Surabaya Islamic boarding school with $p=0,000<0.05$. The strength of the relationship between variables in the correlation phi obtained a very close value of 0.771. The conclusion of the research is the participation of female students in assisting reproductive health education on a regular basis will be able to determine the selection of sexual life. For this reason, companion expertise is needed in providing peer education through methods that attract students to follow mentoring to the end.
\end{abstract}

Keywords: Health Education, Reproduction, Decision Making

\begin{abstract}
ABSTRAK
Menumbuh-kembangkan kesadaran terhadap perilaku sehat bagi remaja, diperlukan kepedulian dan pemahaman yang benar sebagai bentuk pelayanan dan penyampaian informasi terhadap pentingnya kesehatan reproduksi sebagai salah satu cara dalam menentukan pilihan masa depan. Bertujuan untuk memberikan pendampingan kepada santriwati tentang pendidikan kesehatan reproduksi melalui pendidikan sebaya selama 12 kali kegiatan yang memberikan kemampuan santriwati dalam pengambilan keputusan terhadap pemilihan kehidupan seksualnya. Jenis penelitian cross sectional. Target sampel sebesar 40 orang dari Populasi sebesar 415 orang, dengan tekhnik simple random sampling. Pengumpulan data menggunakan kuesioner. Tabulasi dan analisis data dengan Chi Square. Hasil penelitian didapatkan sebagian besar (65\%) responden tidak rutin mengikuti pendampingan melalui pendidikan sebaya, sebagian besar (52,5\%) responden tidak mampu mengambil keputusan, uji chi square didapatkan hubungan yang bermakna antara
\end{abstract}


pendampingan pendidikan kesehatan reproduksi dengan kemampuan pengambilan keputusan terhadap pemilihan kehidupan seksual santriwati di pondok pesantren mahasiswa Al-Jihad Surabaya dengan nilai $\mathrm{p}=0.000<0,05$. Kekuatan hubungan antar variabel pada korelasi phi diperoleh nilai yang kuat yaitu 0,771. Kesimpulan penelitian yaitu keikutsertaan santriwati terhadap pendampingan Pendidikan kesehatan reproduksi secara rutin akan mampu menentukan pemilihan kehidupan seksual. Oleh karena itu, perlu keahlian pendamping dalam memberikan pendidikan sebaya melalui metode yang menarik minat santriwati untuk mengikuti pendampingan sampai tuntas.

Kata kunci: Pendidikan Kesehatan, Reproduksi, Pengambilan Keputusan

\section{PENDAHULUAN}

Pendidikan kesehatan reproduksi bagi remaja merupakan upaya dalam memberikan peningkatan pemahaman terhadap pengetahuan, perilaku, dan sikap positif terhadap seseorang tentang seksual normal, serta peningkatan derajat reproduksinya. Penting diberikan pendidikan kesehatan reproduksi di lingkungan pesantren yang sebagian besar memiliki santri pada usia remaja/dewasa awal. Merujuk pada data yang disampaikan dalam IAWG, 2016 bahwa Lebih dari 340 juta kasus baru penyakit menular seksual setiap tahun, 20 juta aborsi tidak aman terjadi kurang dari 55.000 setiap hari per tahun, yang berujung dengan 80.000 kematian ibu dan diperkirakan setiap tahun puluhan ribu perempuan dan anak perempuan menjadi korban penyerangan seksual.

Meskipun santriwati adalah mahasiswa yang sedang melangsungkan studi di perguruan tinggi, kebutuhan pendidikan dan pemahaman yang benar tentang kesehatan reproduksi pada santriwati juga diperlukan. Layaknya seorang mahasiswa secara umum, para santri juga berkesempatan bergaul dengan lawan jenis di luar pondok secara mudah.
Aktivitas pembelajaran di pondok secara umum meliputi pembelajaran secara kontemporer dan mengaji kitab kuning. Belum diterapkannya pembelajaran pesantren yang membahas kesehatan reproduksi menyebabkan santriwati kurang memahami risiko yang dapat ditimbulkan seperti; cara menjaga kebersihan dan kesehatan organ reproduksi, aktivitas yang membahayakan organ seksual ataupun kehamilan yang tidak diinginkan.

Pemberian pendampingan pendidikan kesehatan reproduksi kepada santriwati melalui Pendidikan sebaya, artinya Pendidikan dilakukan oleh santri untuk santri yang diikuti dengan pendampingan oleh fasilitator, hal tersebut dilakukan guna memudahkan dalam memahami, mengungkapkan dan saling terbuka satu sama lain, sehingga diharapkan santriwati mampu bertindak dengan benar dan dapat mengambil keputusan dalam perilaku kehidupan seksual santriwati di Pondok Pesantren Al Jihad Surabaya.

Pendidikan sebaya merupakan salah satu dari strategi pembelajaran yang berbasis active learning. Melalui pendekatan pendidikan sebaya didapatkan beberapa keuntungan, antara 
lain yaitu melalui pendidikan sebaya dapat menyampaikan pesan sensitif di dalamnya, merupakan peran serta masyarakat dalam mendukung dan melengkapi program lain yang berkaitan dengan strategi masyarakat lainnya, menjadi kelompok target yang lebih merasa nyaman berdiskusi dengan sebaya terutama mengenai masalah mereka seperti seksualitas, serta dapat memberikan pelayanan besar yang efektif dengan biaya yang sedikit.

Keputusan yang dihasilkan dari proses berpikir dan diwujudkan dalam sebuah perbuatan disebut pengambilan keputusan. Salah satu fungsi dari berfikir adalah menetapkan keputusan. Pengambilan keputusan membutuhkan proses pemikiran kritis. Berikut adalah peran pemikiran kritis jika dilihat dari proses pengambilan keputusan, diantaranya: pertama, membantu mengindentifikasi masalah yang dihadapi, kedua, membantu mengumpulkan informasi yang relevan, ketiga membantu menganalisis alternatif pemecahan masalah untuk menentukan pilihan terbaik dan keempat, membantu mengevaluasi keputusan yang sudah diambil. ${ }^{1}$

\section{METODE PENELITIAN}

Jenis penelitian yang digunakan adalah metode survei analitik melalui pendekatan cross sectional guna mengetahui hubungan antara pendampingan pendidikan kesehatan reproduksi dengan kemampuan pengambilan keputusan dalam kehidupan seksual santriwati di Pondok Pesantren Al Jihad Surabaya. Penelitian ini dilaksanakan pada bulan AprilJuni 2019 dengan menggunakan alat bantu kuesioner. Populasi target seluruh santriwati pondok al Jihad sebesar 415 santriwati, sampel sebesar 40 orang dengan simple random sampling. Tabulasi dan analisis data dengan Chi Square dan uji korelasi phi.

\section{HASIL DAN PEMBAHASAN}

\section{Karakteristik Responden Penelitian}

Karakteristik umur menurut Hurlock, terdiri dari 15-18 tahun (Remaja tengah), 18-21 tahun (Remaja akhir), 22-25 tahun (Dewasa muda). ${ }^{2}$ Berdasarkan UU No. 20 Tahun 2003 tentang Sistem Pendidikan Nasional, kategori tingkat pendidikan terdiri dari Pendidikan Dasar, Pendidikan Menengah dan Pendidikan Terakhir. Karakteristik responden dapat dijelaskan pada Tabel 1 berikut ini.

Tabel 1. Distibusi Frekuensi Karakteristik Responden di Pondok Pesantren Al Jihad Surabaya

\begin{tabular}{lrr}
\hline Karakteristik & F & $(\%)$ \\
\hline 1. Umur & & \\
$\quad$ a. Remaja akhir (18-21 tahun) & 18 & 45,00 \\
b. Dewasa muda (22-25 tahun) & 22 & 55,00 \\
\hline Jumlah & 40 & 100,00 \\
\hline 2. Pendidikan Terakhir & & \\
a. Pendidikan Dasar & 0 & 0,00 \\
b. Pendidikan Menengah & 3 & 7.50 \\
c. Pendidikan Tinggi & 37 & 92.50 \\
\hline Jumlah & 40 & 100,00 \\
\hline 3. Informasi pertama & & \\
$\quad$ a. Oorang tua & 11 & 27.50 \\
b.Ssekolah & 23 & 57.50 \\
$\quad$ c. Tteman & 1 & 2.50 \\
d.Iinternet & 5 & 12.50 \\
\hline Jumlah & 40 & 100,00 \\
\hline
\end{tabular}


Berdasasarkan Tabel 1. menunjukkan bahwa sebagian besar $(55 \%)$ responden berumur 22-25 tahun atau dewasa muda dengan hampir seluruhnya $(92,5 \%)$ pendidikan terakhir tinggi dan sebagian besar $(57,5 \%)$ memperoleh informasi pertama di Sekolah.

\section{Karakteristik responden berdasarkan} pendampingan Pendidikan kesehatan reproduksi

Tabel 2. Pendampingan Pendidikan Kesehatan Reproduksi di Pondok Pesantren Al Jihad Surabaya

\begin{tabular}{ccr}
\hline Mengikuti pendampingan & $\mathrm{F}$ & $(\%)$ \\
\hline \multicolumn{1}{c}{5 pertemuan } & 26 & 65.00 \\
$>5$ pertemuan & 14 & 35.00 \\
\hline Total & 40 & 100.00 \\
\hline
\end{tabular}

Berdasarkan Tabel 2. menunjukkan bahwa sebagian besar $(65 \%)$ responden mengikuti pendampingan $<5$ (kali) pertemuan.

3. Karakteristik responden berdasarkan kemampuan pengambilan keputusan

Tabel 3. Kemampuan Pengambilan Keputusan di Pondok Pesantren Al Jihad Surabaya

\begin{tabular}{lrr}
\hline $\begin{array}{l}\text { Kemampuan pengambilan } \\
\text { keputusan }\end{array}$ & $\mathrm{F}$ & $(\%)$ \\
\hline \multicolumn{1}{c}{ Tidak Mampu } & 21 & 52.50 \\
$\quad$ Mampu & 19 & 47.50 \\
\hline Total & 40 & 100.00 \\
\hline
\end{tabular}

Berdasarkan Tabel 3. menunjukkan bahwa sebagian besar $(52,5 \%)$ responden tidak mampu dalam mengambil keputusan terhadap pemilahan kehidupan seksual.

\section{Analisis Hubungan antara pendampingan pendidikan kesehatan reproduksi dengan pengambilan keputusan santriwati di Pondok Pesantren Al Jihad Surabaya.}

Tabel 4. Hubungan antara Pendampingan Pendidikan Kesehatan Reproduksi dengan Pengambilan Keputusan Santriwati di Pondok Pesantren Al Jihad Surabaya

\begin{tabular}{|c|c|c|c|c|c|c|}
\hline \multirow{3}{*}{$\begin{array}{l}\text { Pendampingan Pendidikan } \\
\text { Kesehatan Reproduksi }\end{array}$} & \multicolumn{4}{|c|}{ Pengambilan Keputusan } & \multicolumn{2}{|l|}{ Jumlah } \\
\hline & \multicolumn{2}{|c|}{ Tidak Mampu } & \multicolumn{2}{|c|}{ Mampu } & & \\
\hline & $\mathrm{n}$ & $\%$ & $\mathrm{n}$ & $\%$ & $\mathrm{n}$ & $\%$ \\
\hline Tidak Rutin & 21 & 52,50 & 5 & 12,50 & 26 & 100,0 \\
\hline Rutin & 0 & 0,00 & 14 & 35,00 & 14 & 100,0 \\
\hline Jumlah & 21 & 52,50 & 19 & 47,50 & 40 & 100,0 \\
\hline Uji statistik chi square & & & & & $\mathrm{P}=0,00$ & \\
\hline OR $(95 \% \mathrm{CI})$ & & & & & 1.9 & \\
\hline Koef. Phi & & & & & 0,771 & \\
\hline
\end{tabular}

Berdasarkan Tabel 4. didapatkan terdapat hubungan yang signifikan antar informasi bahwa: dari 40 responden yang variable dependen dan independen dengan nilai mengikuti pendampingan sebagian besar $(65 \%) \quad \mathrm{p}=0.000<0,05$. Kekuatan hubungan antar responden tidak rutin mengikuti pendampingan, variabel pada korelasi phi diperoleh nilai yang sebagian besar $(52,5 \%)$ responden tidak mampu sangat erat yaitu 0,771 . mengambil keputusan, Hasil Uji didapatkan 


\section{Pembahasan}

Hasil penelitian didapatkan bahwa sebagian besar $(65 \%)$ responden tidak mengikuti pendampingan dengan rutin atau kurang dari 5 (kali) pertemuan dari 12 (dua belas) pertemuan yang diagendakan, dan sebagian besar (52,5\%) responden tidak mampu mengambil keputusan terhadap pemilihan kehidupan seksual. Hal ini diakibatkan santriwati belum merasakan manfaat dari pemahaman tentang pendidikan kesehatan reproduksi yang akan diberikan dan sangat dibutuhkan oleh seseorang.

Fine dan McClelland menyebutkan bahwa pada saat memberikan pendidikan seksualitas perlu juga mendiskusikan tentang hasrat seksual yang dialami oleh remaja agar santriwati mampu menanamkan subjektivitas dan tanggung jawab sebagai makhluk seksual. ${ }^{3}$ Hal tersebut menitikberatkan terhadap pentingnya menjadikan remaja sebagai makhluk seksual. Pendidikan seksualitas dalam konsep yang komprehensif dengan berbasiskan hak, ditujukan agar remaja memiliki pengetahuan, keterampilan, sikap, dan nilai-nilai yang mereka butuhkan untuk mampu bersikap dan mengambil keputusan dalam menikmati masa remaja dengan seksualitas mereka baik secara lahir maupun bathin.

Leung \& Lin menjelaskan bahwa pendidikan seks secara luas mencakup program dan intervensi pendidikan di seluruh konteks sekolah, keluarga, dan masyarakat. ${ }^{4}$ Di
Hongkong, selain pendidikan formal di sekolah, ada juga program dan kegiatan yang dikembangkan dan dikelola oleh biro pemerintah dan organisasi lokal Pendidikan seks telah didefinisikan sebagai pendidikan yang mengakui dan mempromosikan hak asasi manusia, kesetaraan gender, pengetahuan, nilainilai, dan keterampilan penting bagi kesehatan seksual dan pencegahan HIV. Selain itu tujuan utama dari intervensi pendidikan kesehatan reproduksi adalah untuk mendukung santriwati dalam membuat keputusan sendiri mengenai kehidupan seksualnya. Pengambilan keputusan haruslah berdasarkan informasi lengkap, yang sesuai dengan usianya dan memenuhi kebutuhan remaja (perkembangan remaja).

Teman sebaya memainkan peran penting dalam kehidupan remaja dengan berperan sebagai pendukung satu sama lain, sebagai model perilaku formal dan informal, dan sebagai sumber informasi tepercaya. Orang lebih cenderung untuk mempersonalisasi pesan, dan dengan demikian mengubah sikap dan perilaku mereka, jika mereka percaya utusan itu mirip dengan mereka dan menghadapi masalah yang sama. ${ }^{5}$

Imron menjelaskan bahwa pendidikan kesehatan reproduksi oleh peer educator diyakini memiliki nilai efektifitas yang tinggi karena para remaja/ santriwati menggunakan bahasa yang kurang lebih memiliki kesamaan pemahaman sehingga informasi yang didapatkan mudah dimengerti. ${ }^{6}$ Melalui teman sebaya 
(peer educator) juga mudah untuk mengemukakan pikiran dan perasaan, pesan yang berssifat sensitif dapat tersampaikan secara lebih terbuka. Transfer pengetahuan seperti ini diharapkan dapat mempengaruhi santriwati yang lainnya dalam bersikap dan berperilaku yang bertanggungjawab sebagai bentuk pengambilan keputusan yang tepat. Tekanan teman sebaya yang positif dapat membangun pengetahuan tentang masalah kesehatan seksual, dan memberikan kesempatan bagi kaum muda untuk berlatih komunikasi dan keterampilan lainnya yang akan membantu mengurangi kemungkinan keterlibatan mereka dalam perilaku seksual berisiko.

Sebagai upaya untuk memastikan bahwa keputusan yang dipilih dapat terinternalisasi dalam jangka panjang, maka keputusan mutlak diambil oleh santriwati secara sukarela dan tidak ada unsur paksaan. Pengambilan sebuah keputusan akan efektif apabila dapat diaplikasikan dalam lingkungan yang mendukung keputusan tersebut. Sa'diyah menuliskan dalam karya ilmiahnya bahwa Engel, Blackwell, dan Miniard mengemukakan tentang proses dalam pengambilan sebuah keputusan oleh seseorang dipengaruhi oleh tiga factor yaitu; faktor lingkungan, faktor perbedaan individu dan proses psikologi. ${ }^{7}$

Menurut Supranto menyatakan bahwa kegiatan pengumpulan informasi dari suatu apresiasi terhadap situasi atau keputusan itu dapat dibuat adalah salah satu komponen terpenting dari proses pengambilan keputusan. ${ }^{8}$ Oleh karena itu, diperlukan pendekatan yang cukup lama untuk bisa memberikan pendidikan kesehatan reproduksi, serta dilakukan oleh teman sebaya sebagai bagian dari proses pendampingannya, agar proses Pendidikan kesehatan reproduksi dengan metode kognitifproaktif ini dapat dilakukan dengan baik sehingga tercipta lingkungan yang mendukung terkait Pendidikan kesehatan reproduksi pada santriwati di pondok pesantren Al Jihad Surabaya.

Kurikulum pendidikan kesehatan reproduksi harus mencakup perkembangan fisik anak hingga remaja, pengembangan sistem reproduksi, hubungan seksual, kehamilan, persalinan, kontrasepsi, hubungan seks dan nilai-nilai moral plus seks dalam konteks Islam. Para responden juga menyarankan bahwa kurikulum pendidikan seks terkait erat dengan konteks Islam dan didukung oleh pengetahuan dari AlQur'an. ${ }^{9}$ Islam mengajarkan kepada umat manusia untuk melakukan tindakan pengambilan sebuah keputusan harus berdasarkan pemikiran sistematis yang bersumber dari dua pedoman yaitu Al-Qur'an dan Al-Hadist. Hal ini dikarenakan keputusan yang akan diambil adalah akan menuntun manusia dalam kebenaran dan terhindar dari kebatilan. Sebagaimana disebutkan pada Al-Qur'an surat Al-Qalam ayat 36 yaitu "atau adakah kamu (berbuat demikian): Bagaimanakah kamu mengambil keputusan? Hendaknya dalam 
setiap pengambilan sebuah keputusan tidak hanya menggunakan logika, namun dibutuhkan juga dalil Aqli mapun Naqli sehingga mampu menemukan ketentuan mana yang harus dipilih.

Kaum muslim tentu tidak asing dengan kisah nabi Adam Alaihissalam dan Ibu Hawa ketika di Syurga. Ketika Allah SWT mempersilahkan mereka berkeliling di syurga namun ada persyaratan yang harus dita'ati yaitu; tidak boleh mendekat, memetik dan memakan buah Khuldi. Namun karena bisikan syaitan akhirnya salah dalam mengambil keputusan. Kisah inspiratif ini disebutkan dalam surat Al- Baqarah ayat 35-37: "Hai Adam, diamilah oleh kamu dan isterimu surga ini, dan makanlah makanan yang banyak lagi baik dimana saja kamu sukai, dan janganlah kamu dekati pohon ini, yang menyebabkan kamu termasuk orang-orang yang zalim". Lalu keduanya digelincirkan oleh syaitan dari surga dan dikeluarkan dari keadaan semula dan kami berfirman: "Turunlah kamu! Sebagian kamu menjadi musuh bagi yang lain, dan bagi kamu ada tempat kediaman di bumi, dan kesenangan hidup sampai waktu yang ditentukan". "kemudian Adam Alaihissalam menerima beberapa kalimat dari Tuhannya, maka Allah menerima taubatnya. Sesungguhnya Allah Maha Penerima taubat lagi Maha Penyayang”.

Pelajaran penting bagi seluruh umat manusia yang ada di bumi ini, untuk menyiapkan diri dalam menghadapi kehidupan serta menjalankan pilihan keputusan yang diambil dan mempertanggungjawabkan dihadapan sang Khaliq.

\section{SIMPULAN DAN SARAN}

Santriwati yang mengikuti pendampingan secara rutin dan mendapatkan pemahaman dalam Pendidikan kesehatan reproduksi akan memiliki kemampuan pengambilan keputusan yang bertanggungjawab dan benar dalam mempengaruhi teman sebayanya.

\section{REFERENSI}

1. United Nations Educational, Scientific and Cultural Organization and United Nations Population Fund. Youth and comprehensive sex education fact sheet. Available at: http://www.un.org/esa/ socdev/documents/youth/factsheets/youths exualityeducation.pdf. Accessed Agustus 4, 2019.

2. Hurlock, E.B. Psikologi Perkembangan. Jakarta: Erlangga. 2011.

3. Pakasi, Diana $\mathrm{T}$ \& Reni.K. Antara Kebutuhan dan Tabu: Pendidikan seksualitas dan Kesehatan Reproduksi bagi Remaja di SMA. Mekarsari Kesehatan. 2013.

4. Leung, H. \& Lin, L. Adolescent Sexual Risk Behavior in Hong Kong: Prevalence, Protacive Factors, and Sex Education Programs. Journal of Adolescent Health. 2019. 64(6), pp.s52-58.

5. Layzer, C., Rosapep, L. \& Barr, S. A Peer Education Program Delivering Highly Reliable Sexual Health Promotion. Journal of Adolescent Health. 2014. 54(3), pp.s7077.

6. Miswanto. Pentingnya Pendidikan Kesehatan Reproduksi dan Seksualitas pada Remaja Jurnal Studi Pemuda. 2014. Vol. 3, No. 2, September 2014. 
7. Sa'diyah. https://eprints.stainkudus.ac.id. pdf. 2015.

8. Lenny Amita W.K. https://lib.unnes.ac.id /26329/1/7101412140.pdf. diakses tanggal 26 Juni 2019. 2016.

9. Talib, J., Maharam M., Ibrahim, M. \& Mohamad, Z., Analysis on sex education in schools across Malaysia. Social and Behavioral Sciences. 2012. 59, pp.340 348.

10. Notoadmodjo, S. Promosi Kesehatan Teori dan Aplikasi. Jakarta: Rineka Cipta. 2010.

11. Kusmiran, E. Kesehatan Reproduksi Remaja dan Wanita. Jakarta: Salemba Medika. 2011.

12. Nurohmah, A. Pentingnya Pendidikan Kesehatan Reproduksi Sejak Dini Dalam Keluarga. 2013.

13. Al Quran dan Terjemahannya. Departemen Agama RI.

14. Undang-Undang Tentang Sistem Pendidikan Nasional. No 20. Jakarta. 2003.

15. Whitaker DJ, Miller KS., Parentadolescent discussions about sex and condoms: Impact on peer influences of sexual risk behaviors. J Adolesc Res. 2000. 15(2). Pp.51-73. 